\title{
Impacto do Espaço Físico Quanto à Aceitação do Acompanhante em Tempo Integral no Ambiente de Terapia Intensiva em Hospital Privado
}

\author{
Ferreira Junior, Firmino Haag; Rodrigues Junior, Wilson; Aguiar, Thais Nogueira; \\ Giusti, Rosilene; Buffon, Marcela \\ Hospital Cruz Azul de São Paulo — afhaag@uol.com.br
}

Objetivo: Avaliar a aceitação dos clientes quanto a permanência em tempo integral diante do espaço físico adequado do centro de terapia intensiva (CTI), verificando se existe relação entre a adesão e o meio. Material e método: Estudo retrospectivo e comparativo de dois períodos de 7 meses, analisando a taxa de aceitação dos familiares quanto a permanência em tempo integral, visando os projetos de humanização institucionais, analisando a diferença na aceitação na permanência no CTI antes e depois da reestruturação física com boxes individualizados, avaliados através de questionário dirigido pela equipe multiprofissional. Resultados: no primeiro semestre de 2012, no antigo CTI, a taxa de adesão na permanência de familiares em tempo integral foi de $48,2 \%$. Após a mudança física, a taxa de adesão subiu para $70,89 \%$, tendo aprovação de $95 \%$ de satisfação do grupo de pacientes analisados. Conclusão: Através dos dados analisados, concluiu-se que o espaço físico adequado favorece a adesão na permanência de familiares em tempo integral, devido promover maior privacidade e conforto durante o período de internação em terapia intensiva.

Ferreira Junior, Firmino Haag; Rodrigues Junior, Wilson; Aguiar, Thais Nogueira; Giusti, Rosilene; Buffon, Marcela. Impacto do Espaço Físico Quanto À Aceitação do Acompanhante em Tempo Integral no Ambiente de Terapia Intensiva em Hospital Privado.. In: Anais do Congresso Internacional de Humanidades \& Humanização em Saúde [= Blucher Medical Proceedings, num.2, vol.1]. São Paulo: Editora Blucher, 2014. ISSN 2357-7282

DOI 10.5151/medpro-cihhs-10347 